\title{
LA MORAL SEXUAL EN CONTEXTO: PUDICITLA Y AI $\triangle \Omega \Sigma$ EN ESPACIOS PÚBLICOS Y PRIVADOS EN HIPÓLITO DE EURÍPIDES Y HEROIDA 4 DE OVIDIO
}

\author{
Sexual morality in context: pudicitia and $\alpha i \delta \omega ́ s ̧$ in public and private spaces in \\ Euripides' Hippolytus and Ovid's Heroides 4
}

\author{
Romina Andrea Flores* \\ Universidad Nacional del Nordeste \\ roandflores@gmail.com
}

Palabras clave

moral sexual;

espacio público;

espacio privado;

Fedra;

Hipólito

\section{Keywords}

sexual morality;

public space;

private space;

Phaedra;

Hippolytus

\section{Resumen}

Las complejidades de la moral humana han sido problematizadas y desarrolladas en la literatura de todos los tiempos. La conducta sexual es, por supuesto, una cuestión que no ha sido ignorada y si bien la moral sexual se centra en la actitud de las mujeres, los hombres también juegan un papel importante: el mito de Hipólito y Fedra es uno de los exempla más notables sobre el pudor y la castidad masculina. En este trabajo analizamos las representaciones sobre la conducta sexual de Fedra e Hipólito en la tragedia Hipólito de Eurípides y en la Heroida 4 de Ovidio. Para ello, confrontamos las concepciones sobre la moral sexual en las culturas griega y latina y los lexemas correspondientes a dicho tópico en ambas lenguas (pudicitia

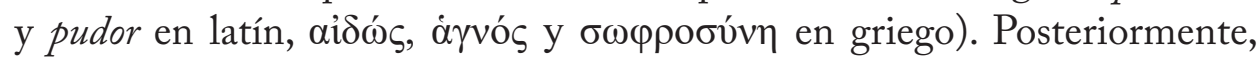
consideramos los espacios de enunciación y acción de los personajes y la problematización sobre las posibles consecuencias de hacer públicas las acciones privadas.

\begin{abstract}
The complexities of human morality have been problematized and developed in the literature of all time. The sexual behaviour is, of course, an issue that has not been ignored and, although moral sexuality focuses on woman's attitude, men play an important role as well: the myth of Hippolytus and Phaedra is one of the most notable exempla of masculine chastity. In this paper, we analyse the representations about Phaedra's and Hippolytus' sexual behaviour in Euripides' Hippolytus and Ovid's Heroides 4. To do this, we confront the conceptions about sexual morality in Greek and Latin cultures, and the corresponding lexemes related to this topic in

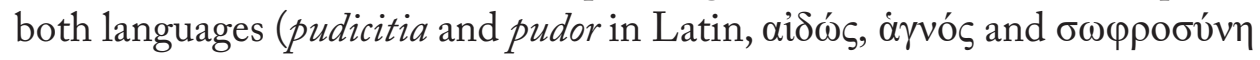
in Greek). Subsequently, we consider the enunciation and action spaces of the characters, and the problematization of the possible consequences of making public private actions.
\end{abstract}




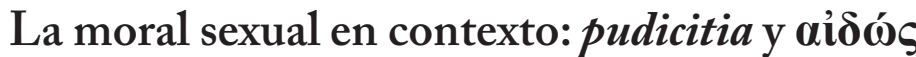 en espacios públicos y privados en Hipólito de Eurípides y Heroida 4 de Ovidio ${ }^{1}$}

Las complejidades de la moral humana han sido problematizadas y desarrolladas en la literatura de todos los tiempos. Dentro de ese campo de interés y análisis, la conducta sexual ha sido un espacio de expresión de las costumbres, las prácticas legitimadas y las sanciones de una sociedad. Si bien en la Antigüedad clásica las problematizaciones sobre la moral y la castidad sexual se centraban en la actitud de las mujeres, el papel de los hombres también era considerado. ${ }^{2}$ En este sentido, el mito de Hipólito y Fedra es uno de los exempla más notables de pudor y castidad masculina.

En el presente trabajo, analizaremos las representaciones de este mito en la tragedia Hipólito de Eurípides y la Heroida 4 de Ovidio, ${ }^{3}$ atendiendo a un tópico central: el pudor. A partir de un análisis comparatista, ${ }^{4}$ consideraremos las diversas concepciones sobre la moral sexual en las culturas griega y latina y los lexemas correspondientes a dicho tópico en ambas lenguas. Esta cuestión es especialmente importante porque el concepto de pudicitia es puramente latino y no presenta antecedente directo en el griego antiguo (Langlands, 2006, p. 2). Por tanto, seguiremos el método filológico intertextual ${ }^{5}$ para seleccionar y traducir los fragmentos más relevantes, prestando especial atención a aquellos que posean el lexema mencionado (pudicitia, esto es, para la Heroida, y pudor, conceptualmente relacionado) y los

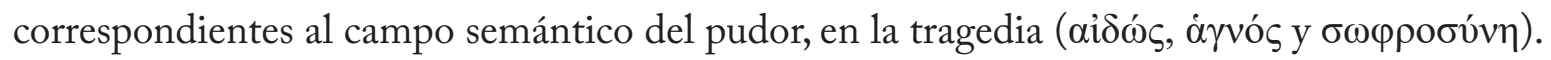

Entendemos por pudor una conducta moral sexual, asociada con determinadas prácticas sociales. Es decir que el pudor está definido por lo público, pero a partir de acciones de carácter privado. Por tanto, nos proponemos analizar las obras elegidas atendiendo a: 1) las diferentes concepciones sobre las conductas sexuales, en particular las nociones morales sobre el pudor; 2) los espacios de enunciación y acción de los personajes; 3) la problematización que se desarrolla sobre la incidencia de la esfera pública en las actividades privadas y las consecuencias de hacer públicas las acciones privadas. Esto nos permitirá poner los textos en diálogo, a fin de categorizar el pudor en función de lo público y lo privado, y describirlo en ambas obras. Finalmente, señalaremos las convergencias y divergencias

1. Agradezco a lxs evaluadorxs anónimxs las sugerencias, los comentarios y la lectura atenta de las traducciones; aportes que me permitieron mejorar el artículo y enriquecer sus fuentes.

2. Para ampliar sobre las diferencias en torno de la moral y la castidad sexual femeninas y masculinas en la Antigüedad clásica, consultar Larson (2012, p. 183-186).

3. El presente trabajo forma parte de un proyecto de investigación más amplio que implica la confrontación de la Heroida 4 con las tragedias que refieren el mismo mito, es decir, Hipólito de Eurípides y Fedra de Séneca, pero cuya concreción se llevará a cabo de forma separada. El análisis de los textos latinos será objeto de un próximo artículo.

4. El comparatismo implica "una forma de investigación literaria que confronta dos o más literaturas" (Franco Carvalhal, 1996, p. 11). Esto posibilita el "diálogo" entre culturas y lenguas diferentes, que entran en relación por uno o varios elementos comunes en textos que, en el marco de una misma literatura, no emergerían como diferentes. De las diversas propuestas metodológicas de este campo de investigación tenemos en cuenta, especialmente, las de Brunel y Chrevrel (1994) y Franco Carvalhal (1996).

5. En este sentido, esta investigación se sustenta formalmente en los procedimientos de la filología clásica, entendida como el estudio detallado de un texto en su lengua original, atendiendo a sus distintos niveles (desde el morfológico y léxico, hasta llegar al sintáctico). A la vez, nos serviremos de la teoría intertextual según ha sido aplicada a los estudios clásicos por Conte (1986, que posiciona al texto en el centro del análisis), Fowler (2000, quien aúna estructuralismo y posestructuralismo en sus consideraciones sobre la jerarquía del texto y la teoría intertextual, respectivamente) y Edmunds (2001, que propone la filología interpretativa como método de aproximación al texto clásico). 
entre tales textos que permitan evidenciar cómo el mito, y el tema que nos compete, es tratado en cada sociedad y resignificado por Ovidio en el marco de la cultura romana de su época.

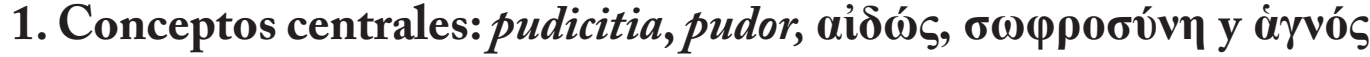

Si bien la moral sobre la conducta sexual fue un tópico muy importante para ambas culturas, solo la latina registra un término propio: ${ }^{6}$ pudicitia. Este lexema poseía un amplio alcance: significaba tanto una virtud moral como una serie de conductas sexuales; refería incluso un culto y el nombre de una diosa que lo personificaba, ${ }^{7}$ entre otras acepciones. ${ }^{8}$ La pudicitia integraba un área de la ética en la que las mujeres jugaban un papel tan importante como los hombres, pues se consideraba que esta virtud fortalecía a ambos géneros por igual; por ejemplo, Hipólito era uno de los paradigmas de la pudicitia y la castidad, junto a Lucrecia y Penélope (Librán Moreno, 2011, p. 345-346). Era a la vez un tema controversial de debate sobre las diferencias entre hombres y mujeres, la relación entre cuerpo y mente, el poder y el estatus social en la cultura romana (Langlands, 2006, p. 2). La pudicitia era la más importante cualidad en la puella y la matrona romanas, se la consideraba exclusiva de personas libres y su pérdida era censurada “con acritud” (Librán Moreno, 2011, p. 345).

En un sentido más específico, sin embargo, pudicitia era un término que siempre refería el comportamiento sexual: el OLD lo define como "Sexual purity, chastity, virtue" (Glare, 2012, p. 1666) y el Diccionario de motivos amatorios en la Literatura Latina como "Temor a recibir una censura merecida de tipo moral" (Librán Moreno, 2011, p. 345). Por tanto, este concepto incluía una serie de conductas morales y sexuales, especialmente, la virginidad, la castidad, la fidelidad y el recato (Librán Moreno, 2011, p. 347). ${ }^{9}$

Especialmente relevante es también el lexema pudor, ${ }^{10}$ conceptualmente relacionado con pudicitia (Langlands, 2006, p. 19). El pudor es una emoción "negativa”, "experienced as a form of fear and discomfort" (Kaster, 2005, p. 28), provocada por la conciencia ante la mirada moralizante de la comunidad, "which placed constraints upon the behaviour of an individual" (Langlands, 2006, p. 18). Es decir, se trata de una emoción que surge y afecta al individuo a partir de las diversas situaciones sociales en las que pudiera intervenir. En este sentido, "pudor is fluid and nuanced, renegotiated by every individual encounter" (Langlands, 2006, p. 19). Otros términos como castitas, sanctitas, abstinentia, continentia, verecundia y modestia se asociaban también a la virtud sexual (Langlands, 2006, p. 2).

\footnotetext{
6. Si bien podemos encontrar términos que compartan su campo semántico, no refieren específicamente a cuestiones de moral sexual, como es el caso de la pudicitia.

7. Sobre el culto a la pudicitia y las cualidades de su diosa, consultar Langlands (2006, p. 37-77).

8. Para ampliar sobre las acepciones del término pudicitia, ver Langlands (2006, p. 2) y Librán Moreno (2011, p. 345-348). 9. Resaltamos aquellas cualidades que resultan relevantes para este trabajo; sin embargo, Librán Moreno (2011) menciona también como propias de una matrona pudorosa: "la honestidad, la castidad, la economía, la modestia, el recato, la fidelidad, la entrega al marido y a los hijos, la vida de servicio, la educación y el agrado, la abnegación, la frugalidad, la obediencia, la dignidad, la tranquilidad y ecuanimidad de ánimo, el sentido del deber, la piedad religiosa, el cuidado de los valores morales" (p. 347).

10. Para profundizar sobre el pudor, consultar Kaster (2005, p. 28-65).
} 
En cuanto a su etimología, pudicitia resulta un término peculiar ya que no presenta un equivalente griego antiguo directo, a diferencia de otros conceptos morales latinos, por lo que se desarrolla independientemente de la tradición filosófica griega. Sin embargo, podemos encontrar

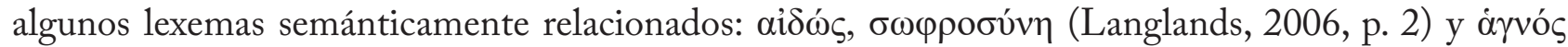
(Segal, 1970, p. 278).

E1 $L S J^{11}$ define la $\alpha \dot{i} \delta \omega \varsigma_{,}{ }^{12}$ en un sentido moral, como "reverence, awe, respect for the feeling or opinion of others or for one's own conscience, and so shame, self-respect (...), sense of honour (...), etc." (PDL, s.f., definición 1). Cairns (2002), por su parte, precisa que es "an inhibitory emotion ${ }^{13}$ based on sensitivity to and protectiveness of one's self-image" (p. 2). Es decir, se trata de una emoción compleja que produce un sentimiento de respeto por los otros, por uno mismo y por la propia conciencia, al mismo tiempo que podía despertar vergüenza o ser motor para cuidar la imagen personal. ${ }^{14}$

Como sucede con pudicitia, este término engloba diversos significados que varían según el contexto. En un sentido estrictamente sexual, encontramos varias coincidencias con el concepto latino: la aỉó́s femenina se caracteriza, esencialmente, por la lealtad al marido o al padre e indica que una persona se halla libre de cualquier imputación de orden sexual (evitable limitando el contacto con el sexo opuesto, de acuerdo con Cairns, 2002, p. 306). Otra similitud refiere a las señales del pudor: para los latinos, el rubor era signo de poseer una pudicitia intacta (Librán Moreno, 2011, p. 345), mientras que los griegos lo consideraban síntoma de $\alpha i \delta \omega ́ s$ (Cairns, 2002, p. 6). Los lexemas se diferencian, no obstante, en su amplitud: mientras que el término latino refiere específicamente a conductas de carácter sexual, aỉós abarca, como hemos indicado, cuestiones que afectan la moral personal en sus distintas formas. Por esta razón, es preciso ampliar el campo semántico griego relacionado con el pudor.

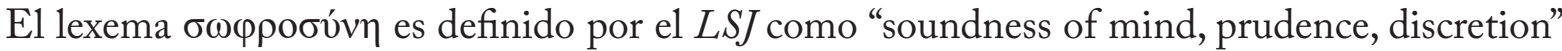
y, en su segunda acepción, como "moderation in sensual desires, self-control, temperance" (PDL, s.f., definición 2). Abrego (2001) le otorga un sentido interior (entendido como una "virtud por naturaleza", proveniente de la propia interioridad) y uno exterior (adquirido por aprendizaje). De igual manera,

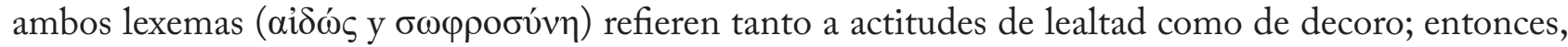
no es de extrañar que se espere que todas las "mujeres respetables" manifiesten cierta compostura o recato (Cairns, 2002, p. 306).

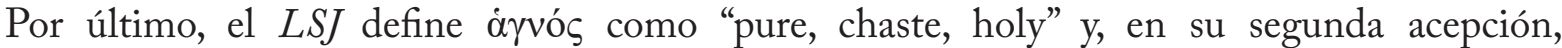
específicamente referido a personas, como "undefiled, chaste (...) pure from blood, guiltless". Su connotación puede variar también según el contexto de enunciación (Segal, 1970, p. 278).

11. Todos los términos referidos al LSJ son recuperados de Perseus Digital Library (www.perseus.tufts.edu).

12. Para ampliar sobre los alcances de este término, consultar Cairns (2002, p. 1-14).

13. El autor aclara que la considera una emoción debido a que se manifiesta con síntomas físicos y fisiológicos (como el rubor) (Cairns, 2002, p. 6).

14. A causa de esta amplitud de sentido la traducción de este término griego es considerada una de las más difíciles (Cairns, 2002, p. 1). 


\section{Caracterización de los espacios. Su relación con el pudor en la Antigüedad clásica}

Para especificar las dimensiones en las que consideraremos los lexemas definidos es preciso delimitar las categorías a trabajar: espacio público y espacio privado. En el siguiente análisis enfatizamos en el aspecto social del pudor ya que, si bien entendemos que las prácticas sexuales forman parte de la esfera privada, la caracterización de esta virtud, por la que una persona era reconocida, dependía de la esfera pública. Vemos en esta dicotomía una tensión que se evidencia en los espacios donde los personajes de las obras seleccionadas se desempeñan o, en el caso de la Heroida especialmente, en la forma en que se refieren los mismos.

Lo público y lo privado son las esferas que constituyen y dividen a la sociedad civil, y su implicancia en la actividad humana ha sido ampliamente estudiada a lo largo de la historia. ${ }^{15}$ Sin embargo, tal distinción era mucho más marcada en la Antigüedad clásica, edad que nos compete, que en el mundo moderno (Arendt, 2009, p. 45). Tales ámbitos se corresponden con los campos de la familia y la política, respectivamente, y son entendidos como "entidades diferenciadas y separadas al menos desde el surgimiento de la antigua ciudad-estado" (Arendt, 2009, p. 41).

En este sentido, consideramos que la esfera privada estaba definida, esencialmente, por el hogar (domus en latín, oĩ la esfera doméstica, el grupo familiar convivía por las necesidades y exigencias para la propia vida (Arendt, 2009, p. 43). Sus miembros vivían en "el centro de la más estricta desigualdad” (Arendt, 2009, p. 44). Por otro lado, es privado también lo que se mantiene en secreto, que se expresa en la intimidad o es compartido solo con personas que no traicionarían tal privacidad.

La esfera pública, en cambio, refiere todo espacio común, fuera del dominio doméstico y, por tanto, compartido con otros miembros de la sociedad con quienes no se mantienen relaciones de parentesco o amistad. En la Antigüedad clásica, se consideraba espacio de circulación libre, ${ }^{16}$ tanto de personas como de discursos, ya que "todo lo que aparece en público puede verlo y oírlo todo el mundo y tiene la más amplia publicidad posible" (Arendt, 2009, p. 59). Es decir, consideramos que también conforma esta esfera todo lo que es de "público conocimiento": lo dicho en un ámbito fuera del hogar o que llegó a oídos de quien no necesariamente lo mantendrá en secreto. En este dominio, los hombres eran "iguales", en la medida que se los considerara "libres"; ${ }^{17}$ esta cualidad presenta una clara distinción entre la vida pública y privada, pues "dentro de la esfera doméstica, la libertad no existía, ya que al cabeza de familia sólo se le consideraba libre en cuanto que tenía la facultad de abandonar el hogar y entrar en la esfera política, donde todos eran iguales" (Arendt, 2009, p. 44-45). A la vez, es el contexto en el que se producen los discursos sociales o políticos, en los que se discute, por ejemplo, sobre cuestiones morales. Es también el espacio de las normas, de la ley, de las sanciones.

15. Para profundizar sobre la incidencia de las esferas pública y privada en la actividad humana, consultar Arendt (2009, p. 37-95)

16. Arendt define lo público como la esfera "de la libertad", cualidad propia del dominio político y social (2009, p. 43).

17. Ser libre implicaba "no estar sometido a la necesidad de la vida ni bajo el mando de alguien y no mandar sobre nadie, es decir, ni gobernar ni ser gobernado" (Arendt, 2009, p. 44). 
Lo público y lo privado se relacionan con el pudor por el aspecto social del concepto, en especial por su estrecha relación con el sentimiento de vergüenza y por el mandato (social) de proteger la propia imagen pública. Precisamente, la vergüenza se asocia con "ser visto, indecorosamente, por personas inadecuadas, en condiciones inadecuadas"(Williams, 2011, p. 131-132).

Atendiendo al contexto grecolatino encontramos diversas posturas en cuanto a los alcances del pudor. Por un lado, como ya se indicó, tanto la pudicitia como el pudor implicaban el temor a ser censurado moralmente. En este sentido, "Fear of disgrace or diminution in the eyes of the community was clearly an important force for the regulation of behaviour in ancient Rome" (Langlands, 2006, p. 18).

Sin embargo, el pudor también era un motivo de alabanza social (Langlands, 2006, p. 31). En consonancia, se trataba de una cualidad personal que debía ser exhibida ante los demás, especialmente por parte de las mujeres casadas. La sociedad romana exigía que las esposas se esforzaran por demostrar su pudor, hasta el punto de que "Ideally pudicitia would shine forth from a married woman; it would turn heads when she walked down the street" (Langlands, 2006, p. 37). No bastaba con regular el comportamiento sexual "en las formas aceptadas", sino que la virtud sexual de la matrona debía ser tan clara como para ser advertida por todos (Langlands, 2006, p. 38). En conclusión, en la Roma antigua la pudicitia era un asunto de público interés.

En el caso de la cultura griega, Dover (1974) afirma que, moralmente, "the hope of praise is a major incentive to virtue and the fear of reproach a major deterrent to wrongdoing" (p. 228). En cuanto a la virtud femenina, los griegos consideraban que debía mantenerse en secreto, como indica la oposición señalada por Langlands (2006): "Whereas Thucydides loudly proclaims the virtues of remaining silent on the subject of women, Roman sources declare that pudicitia must be publicised" (p. 39). Es decir, el pudor ocupaba el ámbito público de las mujeres romanas, pero no el de las griegas.

Esta confrontación entre los alcances de la moral sexual en las culturas romana y griega nos permite cerrar el marco teórico preciso para dar inicio al análisis. A partir de esta aproximación a las diferencias culturales en cuanto a la moral vinculada con la conducta sexual, analizamos las distintas manifestaciones del pudor y su relación con los espacios públicos y privados en las obras seleccionadas.

\section{Tensiones entre lo público y lo privado. Manifestaciones del pudor en las obras seleccionadas}

Para describir el tratamiento de los espacios en la tragedia y en la epístola debemos tener en cuenta, en primer lugar, los géneros correspondientes. La tragedia ática implica siempre la intervención pública, la exposición a las opiniones del público y la interpelación a los espectadores, a quienes se considera "a community that becomes engaged in the drama and that thereby participates in the inner world that is the pathos or 'suffering' of the hero" (Nagy, 2013, p. 459). Se representa solo lo que sucede en el exterior, lo que pasa dentro es narrado por algún personaje. Es decir, lo público, inherente a este género, se ve representado en el espacio del escenario y lo privado, lo no visto, en el del palacio. 
A diferencia de lo que ocurre en la tragedia, la epístola18 "mantiene en tensión lo privado y lo público, es secreta y sociable al mismo tiempo" (Bouvet, 2006, p. 71) ya que es accesible a cualquiera que disponga de ella y sepa leer. ${ }^{19}$ Sin embargo, se corresponde con la esfera privada siempre y cuando su contenido no se divulgue; a la vez, porque es el lugar para la palabra íntima -quizás solo superado en intimidad por la conversación cara a cara- y su discurso, "inherentemente privado" (Bouvet, 2006, p. 71), pertenece a una sola voz enunciadora.

Las Heroidas, a la vez, se inscriben dentro del género elegíaco como una creación ovidiana que opone al punto de vista masculino la visión de la mujer (von Albrecht, 1994, p. 730) a través de "The exploration of intense emotion, erotic and romantic grief, introspection and personal feelings given precedence over political and social concerns" (Sharrock, 2012, p. 71), aspectos que refieren también a lo público y lo privado.

A pesar de tales diferencias, ambas obras comparten, a rasgos generales, el mismo contexto: durante la ausencia de Teseo, Fedra se enamora de Hipólito y, de una forma u otra, el héroe se entera de sus sentimientos. En la tragedia, por intervención de la Nodriza; en la epístola, por las mismas palabras de la reina.

De los diversos temas que se desarrollan en el Hipólito ${ }^{20}$ de Eurípides Segal (1970) sostiene que

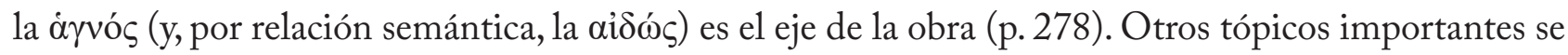
presentan en los binomios "interno-externo, sabedoria-ignorância, natureza-lei e privado-público que perpassam todo o drama, mesmo após a morte de Fedra” (da Silva, 2019, p. 101). En conjunto, la obra puede ser considerada "a study of the effects of conflict and repression in the sphere of sex" (Dodds, 1925, p. 104).

La Heroida 4 forma parte de un conjunto de textos epistolares ficticios escritos por mujeres de la tradición clásica o la historia (como es el caso de Safo) cuya autoría pertenece a Ovidio, cuya voz se halla subsumida frente a las de las heroínas (Sharrock, 2012, p. 71). Son las mismas heroínas quienes escriben cartas en las que relatan, en primera persona, su perspectiva sobre los hechos, lo que les otorga un papel mucho más activo que el que poseían en la tradición anterior (Camino Plaza, 2015, p. 4). Sin embargo, la emisora de la carta que nos compete se diferencia del resto de las heroínas ya que ellas "intentan hacer volver al héroe ausente o pérfido, de cuyo descuido o traición han sido víctimas", en cambio "Fedra lo que pretende es conquistar a su hijastro Hipólito: no se trata de recuperar un amor perdido, sino de iniciar una relación prohibida" (Cortés Tovar, 2012, p. 248). Teniendo esto en cuenta,

18. Consideramos que, dentro del contexto ficcional de las Heroidas, las heroínas escriben cartas de naturaleza privada a los héroes. Sin embargo, como señala Bouvet (2006, p. 71), son accesibles a cualquiera que disponga de ellas, por ejemplo, Penélope entrega sus cartas a los viajeros que llegan a Ítaca para que se las den a Odiseo.

19. Para profundizar en la ambigüedad del género epistolar entre lo público y lo privado, consultar Bouvet (2006, p. 71 y ss.). 20. Tratamos con una segunda versión euripideana de esta tragedia. La primera, titulada Hipólito velado, fue mal recibida por el público porque Fedra le revelaba abiertamente sus sentimientos a Hipólito (da Silva, 2019, p. 101). Si bien no podemos considerar este texto en el análisis, dicha circunstancia resulta relevante para demostrar la importancia de la moral sexual femenina en la esfera pública. 
de sus labios, sino de los de la Nodriza (E. Hipp. 353). El temor a la censura social propio del aíó́ le impide pronunciarlo en voz alta. ${ }^{25}$

A partir de este momento, la pasión amorosa de Fedra pasa del dominio de lo privado al de lo público. Como indica da Silva (2019): "A paixão da rainha é revelada lentamente; neste caso, a passagem do privado para o público está associada ao seu segredo que se espalha até que toda a cidade de Trezena tenha conhecimento do ocorrido” (p. 102). Atendiendo a la tensión entre los espacios que implica este traspaso, podemos analizar las manifestaciones que los personajes emiten sobre el pudor.

Para ello, resulta especialmente relevante el discurso de Fedra sobre los dos tipos de aídós:

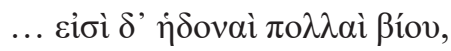

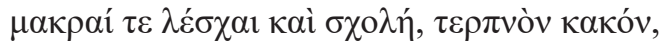

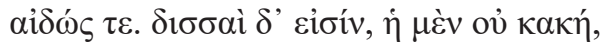

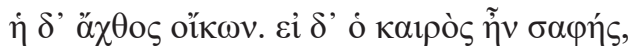

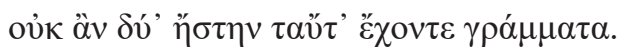

(E. Hipp. 383-387)

Existen muchos placeres en la vida, la charla larga y el ocio, agradable mal, y el pudor. Que tiene dos formas, uno en verdad no es malo y el otro es el suplicio de las casas. Pero si su proporción fuera clara no habría dos conceptos con las mismas letras.

Los versos citados presentan diversos problemas para los traductores, por lo que hay numerosos trabajos en torno de tal controversia. ${ }^{26}$ Para el siguiente análisis, tenemos en cuenta la interpretación de Méridier ad loc (citado en Williams, 2011, p. 268), que indica: "La mauvaise honte, c'est-à-dire cette lache complaisance aux entraînements du dehors qui fait oublier le devoir (et empéche de faire le bien), tandis que la bonne honte, la pudeur, retient contre le mal". En otras palabras, el pudor auténtico ${ }^{27}$ es aquel que impide actuar erróneamente, que lleva por acciones moralmente correctas y cuya motivación es verdadera; por el pudor inauténtico, en cambio, se actúa falsamente y por influencia de otras personas. En ambos sentidos encontramos los ámbitos propuestos en este análisis. El pudor auténtico se manifiesta tanto en la esfera pública como en la privada, ya que las acciones son realizadas sinceramente, a partir de lo que uno íntimamente siente que es correcto. El pudor inauténtico, motivado muchas veces externamente, se muestra en la esfera pública pero no tiene correspondencia en la privada.

Para este trabajo, consideramos que otra lectura posible del pudor inauténtico es el miedo a la censura social como motivo para realizar acciones incorrectas. Esto es, actuar indebidamente en pos de evitar el rechazo público. Esta lectura se corresponde con las palabras de Fedra, siempre preocupada

25. En este sentido, no coincidimos con la lectura de Nápoli (2007) que considera que Fedra declara "abiertamente" sus sentimientos por temor al pudor falso (p. 188-189).

26. Para ampliar sobre otras lecturas de este pasaje, consultar Dodds (1925), Kovacs (1980), Nápoli (2007 p. 188-189), Segal (1970, p. 283-288) y Williams (2011, p. 265-271).

27. Retomamos la interpretación propuesta por Nápoli (2007, p. 188-189). 
por cuidar su buena imagen en nombre de sus hijos y porque sus malas acciones no sean conocidas:

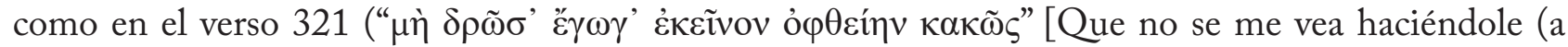

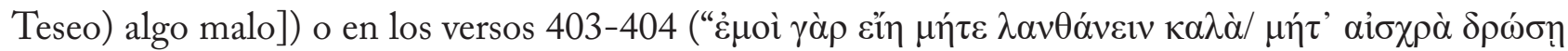

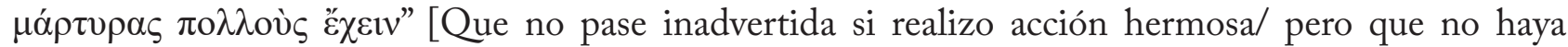
muchos testigos si hago algo deshonroso]). Fedra teme que sus sentimientos sean públicos ya que las cuestiones de moral sexual femenina no debían ser conocidas. ${ }^{28}$ De cualquier modo, el Coro confirma sus

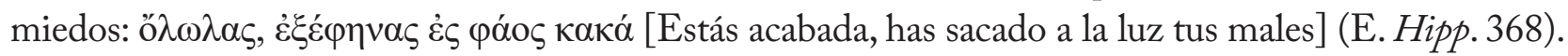

Las consecuencias de manifestar públicamente lo indebido son explicitadas por Hipólito: el héroe no duda en declarar que su $\sigma \omega \varphi \rho \sigma v$ v $\eta$ es natural y que la manifiesta en todos los ámbitos:

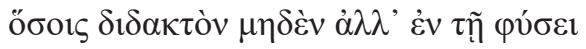

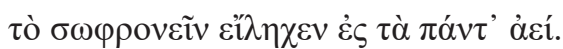

(E. Hipp. 79-80)

Solo para quienes no aprendieron nada sino que son por naturaleza moderados en todas las formas.

Además, indica que esta cualidad es mayor en él que en el resto de los mortales pues es el único que puede hablar con Ártemis (E. Hipp. 85-86) y se jacta de su áyvó como motivo por el que niega el saludo a Afrodita, a pesar de las advertencias de su sirviente:

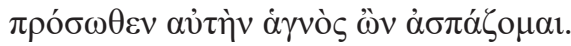

Desde lejos la saludo porque soy casto.

Estas declaraciones y acciones son desencadenantes de la ira de Afrodita. Sin embargo, esta situación es replicable en otros ámbitos y no necesariamente exclusiva del accionar de un dios. ${ }^{29}$ Williams (2011) indica que llevar a cabo acciones que la vergüenza debía evitar produce vé $\mu \varepsilon \sigma ı$, entendida como, "en función del contexto, desde el horror, el desprecio y la malicia hasta una rabia y una indignación justicieras” (p. 134).

Fedra también se declara pura, pero solo en sus acciones (a diferencia de Hipólito, que dice serlo en todas las formas):

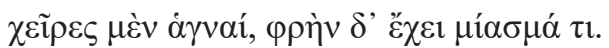

(E. Hipp. 317)

En verdad mis manos están puras, pero mi corazón está contaminado.

28. En este sentido interpretamos los citados versos E. Hipp. 293-296.

29. Precisamente, esto sucede con Teseo quien, sintiéndose traicionado, se venga de Hipólito por intervención de Poseidón. 
Fedra afirma en este pasaje que no ha hecho nada indebido pues ni siquiera ha confesado aún lo que siente. Su falta sigue en secreto y, por tanto, es privada. El paso de esta esfera a la pública desencadena el conflicto y el final trágico de ambos protagonistas.

Además, este fragmento euripideo es intertextualmente relevante porque en la Heroida la falta de Fedra se efectúa por sus propias manos ya que declara sus sentimientos a través de la carta (Ov. epist. 4.175-176). Este es un punto muy importante para comprender la resignificación que realiza Ovidio: en esta versión del mito, no hay intermediarios entre Fedra e Hipólito, él conoce sus sentimientos por las propias palabras de la reina, pero no dichas en voz alta sino a través de la escritura.

En este texto, el ámbito privado es el inherente, considerando las siguientes condiciones: la epístola refiere a una sola voz enunciadora y a un solo receptor; y faltan intermediarios entre los protagonistas, lo que posibilita que su discurso se mantenga dentro de este dominio (hecho del que, veremos, Fedra busca obtener una ventaja). Pero esa voz, a la vez, alude a otras, a la esfera pública y a la influencia del pudor en esta.

Las primeras referencias a la moral sexual se dan ya al comienzo de la carta. Fedra explica la motivación de la misiva, que sustituye una conversación directa:

Ter tecum conata loqui ter inutilis haesit

lingua, ter in primo restitit ore sonus.

qua licet et sequitur, pudor est miscendus amori;

dicere quae puduit, scribere iussit amor.

(Ov. epist. 4.7-10) $)^{30}$

\begin{abstract}
Tres veces intenté hablarte, tres veces encerrada e inútil se mantuvo mi lengua, tres veces se opuso mi boca a producir sonido.

De ser posible, el pudor debe acompañar y unirse al amor;

Lo que por pudor no dije, el amor me ordena escribirlo.
\end{abstract}

La pudicitia impide que la esposa de Teseo declare sus sentimientos a su amado. Fedra reconoce que los sentimientos de pudor y amor deberían converger (como ya indicamos, se esperaba que la matrona fuera pudorosa) pero, cuando se oponen, el amor vence y ordena. En ambos casos, la tragedia y la epístola, la confesión se da por influencia de otros, no por voluntad propia. Podemos ver así cómo la reina trata de seguir los mandatos de la moral sexual, pero queda expuesta por confiar en quien no debía, en el primer caso, o se ve obligada por una fuerza mayor, en el segundo. En los versos siguientes (Ov. epist. 4.11-14) Fedra aclara, además, que no se trata solo de lo que siente, sino que la coacciona el mismo dios Amor. De esta forma, se excusa por su accionar pues

She argues from the great power of that deity, who was in a manner irresistible, and from whose darts even the great gods themselves were not exempted. It was therefore less blameable in a weak woman to give way to him. (Mahoney, 1813, p. 28)

30. Las citas latinas de Ov. epist. han sido tomadas de la edición crítica de Showerman y Goold (1977). La autoría de las traducciones castellanas me pertenece. 
Al igual que en la tragedia, Fedra sufre de enfermedad de amor ${ }^{31}$ y mantiene la causa en silencio: me tacitam conscius urit amor / Solo yo conozco en silencio el amor que me consume (Ov. epist. 4-52). Sin embargo, con la carta como medio, Fedra expresa lo que no puede decir en voz alta. Busca, entonces, convencer a Hipólito de consumar una relación ilícita. Su principal argumento es que la relación que ya comparten ocultaría su falta:

nec labor est celare, licet peccemus, amorem.

cognato poterit nomine culpa tegi.

viderit amplexos aliquis, laudabimur ambo;

dicar privigno fida noverca meo.

(...) ut tenuit domus una duos, domus una tenebit;

oscula aperta dabas, oscula aperta dabis;

tutus eris mecum laudemque merebere culpa,

tu licet in lecto conspiciare meo.

(Ov. epist. 4.137-140 / 143-146)

Y no es difícil ocultar el amor, aunque cometamos una falta.

El nombre de nuestro parentesco podrá cubrir la culpa.

Quienes vean nuestros abrazos, nos alabarán a ambos;

dirán que tenemos la confianza de una madrastra a un hijastro.

(...) Si una casa nos albergó a ambos, una casa nos albergará;

si me diste besos sin ocultarlos, me darás besos sin ocultarlos;

conmigo estarás protegido, tu culpa merecerá alabanza,

así te vean en mi cama.

La reina entiende los beneficios que, en su caso, conlleva el hogar compartido y el parentesco, y desea explotarlos. Su argumento es sencillo: mientras se mantengan en el ámbito privado, el doméstico, las muestras de afecto serán interpretadas en función de la relación familiar, incluso aunque su cariño sea conocido. Fedra juega con los límites entre estas esferas y, aprovechándose del encuentro -o incluso de la contaminación entre ambas-, extiende las normas de lo privado a lo público. Además, confesado su amor, el pudor ya no la afecta, como indica en el siguiente pasaje:

depudui, profugusque pudor sua signa reliquit.

(Ov. epist. 4.155)

Ya no siento vergüenza, el prófugo pudor dejó atrás sus huellas. ${ }^{32}$

En ambas versiones, la reina sufre por lo que siente, se considera víctima de la intervención de un dios, actúa según las convenciones sociales (aunque sea solo por un lapso determinado) y se preocupa por mantener intacta su buena imagen pública. Sin embargo, como demuestran los fragmentos citados,

31. Para ampliar sobre este tópico, consultar Traver Vera (2011, p. 259-262).

32. Librán Moreno (2011) interpreta que Fedra ya no puede ruborizarse pues, como ya hemos indicado, esa era una de las marcas del pudor (p. 348). 
la Fedra ovidiana desea y está dispuesta a concretar su pasión, a diferencia de la euripideana que prefiere morir antes que cometer tal falta.

El cambio esencial entre ambos textos reside en el rol activo que desempeña la Fedra latina, pues decide "tomar cartas" en el asunto y busca una solución con la que puedan estar juntos sin manchar su fama. Ovidio resignifica el mito ofreciendo nuevos datos (como el hecho de que la reina había tratado de declararse ya en tres ocasiones distintas) y una nueva caracterización de la protagonista femenina.

Teniendo en cuenta el marco teórico desarrollado previamente, entendemos que esta resignificación responde, en primer término, a la elección de un género literario distinto: la elegía presenta nuevas oportunidades para explorar el mito. En este género romano, el poeta no alaba el pudor femenino a ultranza debido a que su intención es ganarse el amor de una mujer. En consecuencia, la puella elegíaca es pudica no al abstenerse de mantener relaciones sexuales, sino al ser fiel a su amado (Librán Moreno, 2011, p. 345). Como Fedra se considera abandonada por su esposo y dice mantenerse “virgen” porque nunca amó (Ov. epist. 4.29-30), su accionar podría corresponderse con ese caso.

Esto conlleva una modificación, a su vez, en la esfera predominante. Como hemos precisado, consideramos que la epístola, atendiendo a las condiciones previamente indicadas, es un género inherentemente privado. Los caracteres de la elegía y la carta permiten (literaria y moralmente) que Fedra se exprese con mayor libertad..$^{33}$

En consonancia, la reina toma un papel activo en la relación amorosa. Como se trata de una representación del mito que recoge datos de versiones precedentes, podemos encontrar su influencia en diversas características de la carta y su escritora ficticia. En este sentido, algunos críticos consideran que la epístola y Fedra presentan características de sus contrapartes masculinas (Davis, 1995, p. 44 y ss.), que la reina es un personaje trágico que busca presentarse como uno elegíaco (Fulkerson, 2005, p. 126) o que Ovidio transmuta el motivo de la caza, que en Eurípides formaba parte de su delirio (E. Hipp. 215-22), en el típico obsequium (devoción a los deseos del amado) de la elegía (Ov. epist. 37-50) (Kenney, 1984, 423). El texto elegíaco retoma los hechos que transcurren en las tragedias griegas y los transforma según sus propias características, pero no la historia: "Elegy in the Heroides can only mislead: it changes everything, but it does not actually change anything” (Casali, 1996, p. 3).

Para completar el análisis, debemos atender a las características de la moral sexual en Roma. En esta cultura, el pudor femenino era un asunto público (al contrario que en la sociedad griega) puesto que las matronas debían demostrar su pudicitia al resto. Esto es, tomaban un rol activo a la hora de definir cómo se presentarían públicamente para defender y denotar que poseían esta virtud. Por tanto, resulta verosímil que Fedra especule sobre su comportamiento sexual, la posibilidad de que sea público y las repercusiones que esto conllevaría.

33. O de que sus palabras sean una mentira, como indica Casali (1996). 


\section{Conclusiones}

Las nociones morales sobre la conducta sexual nos permiten conocer diversos aspectos de las culturas que las desarrollan. Las características vistas en las obras seleccionadas demuestran que tales particularidades existen aun entre culturas como la griega y la latina.

Con los ámbitos público y privado como marco, hemos descrito la influencia de estas esferas en el comportamiento sexual. En el caso de la tragedia griega, el espacio privado es el lugar del silencio y el que permite resguardar la moral pública. Allí, Fedra mantiene en secreto lo que siente, Hipólito promete no divulgarlo y, tras la traición, la reina se suicida para salvar su honor. En el espacio público, escenario donde se desarrolla lo representado, los discursos se conocen, se juzgan y se comparten, con las consecuencias que estas acciones conllevan. La influencia de la moral sexual griega destaca, sobre todo, en dos momentos: al impedir que Fedra declare abiertamente sus sentimientos y al castigar no solo el amor impúdico de la reina sino también la conducta célibe de Hipólito.

En el caso de la epístola, en cambio, tales espacios se entremezclan. El género epistolar, inherentemente privado, refiere lo público y problematiza las consecuencias de que las acciones privadas sean conocidas -incluso aquellas realizadas en el ámbito doméstico-. La reina se aprovecha de esto y extiende las normas de lo privado a lo público, en una actitud completamente contraria a la de la Fedra griega. La enamorada romana ya no reniega de sus sentimientos, sino que hace acopio de los mismos y los afronta. En la carta, expone cómo sus intercambios amorosos podrían ser públicos y que, aún así, su falta pasaría inadvertida, puesto que sus encuentros serían vistos como meras muestras de afecto entre familiares. Las cualidades de la pudicitia, especialmente en los géneros epistolar y elegíaco, le permiten, literaria y moralmente, expresar sus deseos y hallar una forma (aunque sea solo en apariencia) de legitimar la relación impudorosa.

\section{Referencias bibliográficas}

Abrego, M. B. (2001). Moralidad interior y exterior en el Hipólito de Eurípides. Ponencia presentada en $I V$ Congresso Nacional de Estudos Clássicos, Ouro Preto, Brasil. Manuscrito no publicado.

Arendt, H. (2009). La condición bumana. Buenos Aires, Paidós.

Bouvet, N. E. (2006). La escritura epistolar. Buenos Aires, Eudeba.

Brunel, P. y Chrevrel, Y. (1994). El hecho comparatista. México, Siglo XXI.

Cairns, D. (2002). Aidos. The Psychology and Ethics of Honour and Shame in Ancient Greek Literature. Oxford, Oxford University Press.

Camino Plaza, L. (2015). Las voces femeninas en las Heroidas de Ovidio. Nuevas aproximaciones a la elegía de mujeres. ArtyHum, 20, 2-12.

Casali, S. (1996). Strategies of tension (Ovid, Heroides 4). The Cambridge Classical Journal, 41, 1-15. DOI:10.1017/S0068673500001905. 
Conte, G. B. (1986). The Rhetoric of Imitation. Genre and Poetic Memory in Virgil and other Latin Poets. Ithaca, Cornell University Press.

Cortés Tovar, R. (2012). Qua licet et sequitur pudor est miscendus amori (Ov. epist. 4.9): la transgresión de los límites y los límites de la transgresión en la carta de Fedra. Cuadernos de Filología Clásica. Estudios latinos, 32 (2), 247-269.

Crane, G. (ed.). Perseus Digital Library. Tufts University. http://www.perseus.tufts.edu.

da Silva, F. (2019). A tensão entre o privado e o público na tragédia "Hipólito", de Eurípides. Boletim de pesquisa nelic, 19 (30), 100-115.

Davis, P. (1995). Rewriting Euripides: Ovid, Heroides 4. Scholia, 4, 41-55.

Dodds, E. (1925). The AI $\Delta \Omega \Sigma$ of Phaedra and the Meaning of the Hippolytus. The Classical Review, 39 (5/6), 102-104. DOI:10.1017/S0009840X00035411.

Dover, K. J. (1974). Greek popular morality. In the time of Plato and Aristotle. Oxford, Blackwell.

Edmunds, L. (2001). Intertextuality and the Reading of Roman Poetry. London, John Hopkins University Press.

Fowler, D. (2000). Roman Constructions: Readings in Postmodern Latin. Oxford, Oxford University Press.

Franco Carvalhal, T. (1996). Literatura comparada. Buenos Aires, Corregidor.

Fulkerson, L. (2005). The Ovidian Heroine as Author. Reading, Writing and Community in the Heroides. Cambridge, Cambridge University Press.

Kaster, R. A. (2005). Emotion, Restraint, and Community in Ancient Rome. Oxford, Oxford University Press.

Kenney, E. J. (1982). Ovid. En Kenney, E. y Clausen, W., The Cambridge History of Classical Literature II: Latin Literature (pp. 420-457). Cambridge, Cambridge University Press.

Kovacs, D. (1980). Shame, Pleasure, and Honor in Phaedra's Great Speech (Euripides, Hippolytus 375-87). The American Journal of Philology, 101 (3), 287-303.

Kovacs, D. (1995). Euripides. 2, Children of Heracles; Hippolytus; Andromache; Hecuba. Cambridge, Harvard University Press.

Langlands, R. (2006). Sexual Morality in Ancient Rome. Cambridge, Cambridge University Press.

Larson, J. (2012). Greek and Roman Sexualities. A Sourcebook. London/New York, Bloomsbury.

Librán Moreno, M. (2011). Pudor. En Moreno Soldevila, R. (ed.), Diccionario de motivos amatorios en la Literatura Latina (Siglos III a. C. - II d. C.) (pp. 345-348). Huelva, Universidad de Huelva.

Mahoney, A. (1813). The Epistles of Ovid. London, Nunn. https://bit.ly/3wmbUro. 
Moreno Soldevila, R. (ed.). (2011). Diccionario de motivos amatorios en la Literatura Latina (Siglos III a. C. - II d. C.). Huelva, Universidad de Huelva.

Nagy, G. (2013). The Ancient Greek Hero in 24 Hours. Cambridge, Harvard University Press.

Nápoli,J.T. (2007). Eurípides. Tragedias I. Alcestis, Medea, Hipólito, Andrómaca. Buenos Aires, Colihue.

Segal, Ch. (1970). Shame and Purity in Euripides' Hippolytus. Hermes, 98 (3), 278-299. https://bit.ly/3tWolsF.

Sharrock, A. R. (2012). Ovid. En Gold, B. (ed.), A Companion to Roman Love Elegy. Blackwell Publishing.

Showerman, G. y Goold, G. (1977). Ovid in Six Volumes. Vol. 1: Epistulae (vel Heroides). Cambridge, Harvard University Press.

Traver Vera, A. (2011). Mal de amores. En Moreno Soldevila, R. (ed.), Diccionario de motivos amatorios en la Literatura Latina (Siglos III a. C. - II d. C.) (pp. 259-262). Huelva, Universidad de Huelva.

von Albrecht, M. (1994). Historia de la literatura romana. Desde Andrónico hasta Boecio. Volumen I. Barcelona, Herder.

Williams, B. (2011). Vergüenza y Necesidad. Recuperación de algunos conceptos morales en la Grecia antigua. España, Machado libros.

* Romina Andrea Flores es estudiante avanzada de la Licenciatura y del Profesorado en Letras (Universidad Nacional del Nordeste), becaria EVC-CIN (2021-2022) e integrante del Proyecto de Investigación 17H014 "Dimensiones monstruosas de la épica y de sus héroes en Heroidas de Ovidio" (Secretaría General de Ciencia y Técnica, UNNE). Ha realizado una Instancia Virtual de Investigación en el Proyecto "Cuerpo y violencia en las narradoras mexicanas del Siglo XXI" (Universidad Veracruzana, México).

RECIBIDO: 26/03/2021

AcEPTAdo: 23/04/2021 